\title{
Evaluation of the clinical characteristics, management, and prognosis of 103 patients with gastric mucosa-associated lymphoid tissue lymphoma
}

\author{
XIAOWU LI ${ }^{1}$, XIANG WANG ${ }^{1}$, ZHONGLI ZHAN $^{2}$, LIANYU ZHANG ${ }^{2}$, BAOCHUN SUN $^{2}$ and YIZHUO ZHANG $^{3}$ \\ ${ }^{1}$ Department of Medical Oncology, Xuzhou Central Hospital, Xuzhou, Jiangsu 221009; \\ Departments of ${ }^{2}$ Pathology and ${ }^{3}$ Hematology, Tianjin Cancer Institute and Hospital, Tianjin 300060, P.R. China
}

Received October 15, 2015; Accepted January 18, 2016

DOI: $10.3892 / \mathrm{ol} .2016 .4124$

\begin{abstract}
The diagnosis of gastric mucosa-associated lymphoid tissue (MALT) lymphoma is difficult owing to its non-specific symptoms and various endoscopic findings. Treatments such as radiotherapy (RT) for localized and chemotherapy (CT) for advanced stages of the disease are employed. The aim of the present study was to examine the clinical characteristics and prognostic factors of Helicobacter pylori (H. pylori) eradication (HPE) in patients with gastric MALT lymphoma. The medical records of 103 patients with gastric MALT lymphoma for the period 2001-2013, were analyzed. The 103 median age of the patients was 53 years and the male to female ratio was 1:1. Serum lactate dehydrogenase and $\beta 2$-microglobulin were within normal range. Macroscopically, the most commonly involved site was the antrum, followed by the corpus and fundus. A total of 97 patients (94\%) tested positive for H. pylori. Forty patients $(39 \%)$ had stage I, 35 patients $(35 \%)$ had local or distant nodal involvement, 20 of 103 patients had stage IIIE (19\%) and 8 of 103 patients had stage IV (7\%) disease. Complete remission, after HPE, was achieved in 54 of the 69 patients $(78 \%)$ that were $H$. pylori-positive and in 2 of the 4 patients $(50 \%)$ that were $H$. pylori-negative. HPE had a superior trend in the $H$. pylori-positive patients although no significant difference was identified in the two groups ( $\mathrm{p}=0.194)$. In patients with advanced disease, the 5-year progression-free survival (PFS) and overall survival (OS) estimates were significantly impro0ved for patients receiving HPE with CT or RT than those receiving CT or RT ( $\mathrm{p}=0.046$ and 0.035 , respectively). The multivariate analysis revealed that, the advanced stages were independently associated with shorter PFS, and the modified-International Prognostic Index (m-IPI) ( $\geq 2)$ was
\end{abstract}

Correspondence to: Dr Xiang Wang, Department of Medical Oncology, Xuzhou Central Hospital, 199 JieFang South Road, Xuzhou, Jiangsu 221009, P.R. China

E-mail: xiangwang958@163.com

Key words: gastric mucosa-associated lymphoid tissue, treatment, prognosis, Helicobacter pylori eradication associated with shorter OS. In conclusion, gastric MALT lymphoma had a favorable outcome with a high OS rate. HPE was an effective treatment for gastric MALT lymphoma. The patients with advanced stages and m-IPI $(\geq 2)$ had a much worse prognosis.

\section{Introduction}

The gastric region is the most frequent site of extra nodal lymphoma (1). Gastric lymphoma, which originates from the mucosa-associated lymphoid tissue (MALT), behaves as an indolent disease and has a favorable long-term prognosis with a 10 -year survival rate of $>90 \%$. Most cases of gastric MALT lymphoma remain localized within the gastric region for many years (2).

Gastric MALT lymphoma is difficult to diagnose due to its non-specific symptoms and various endoscopic findings (3). Helicobacter pylori (H. pylori) infection is associated with gastric MALT lymphoma. Therefore, H. pylori eradication (HPE) is a potentially effective therapeutic option in cases of early-stage, low-grade gastric MALT lymphoma. This leads to remission in $>75 \%$ of patients (4). However, the management strategy for $H$. pylori-negative, lymphoma residuals, or recurrent disease is not well-defined. Treatment guidelines recommend a stage-dependent approach, favoring radiotherapy (RT) for localized and chemotherapy (CT) for advanced stages of the disease (5). However, clinicians and patients have to balance the risks and benefits of specific treatments without high-level evidence or long-term survival data. Different prognostic factors for gastric MALT lymphoma have been identified, including neoplasia stage, depth of infiltration in the gastric wall, localization in the stomach, and patient ethnicity (6-9).

We conducted a retrospective analysis in the patients with gastric MALT lymphoma to analyze the clinical characteristics, prognostic factors and long-term outcomes.

\section{Materials and methods}

Ethics approval. The Ethics Committee of the Tianjin Medical University Cancer Institute and Hospital approved the current study. Patient records/information were anonymized prior to 
the analysis. Written informed consent was provided by the participants in order for their clinical records to be used in the current study.

The hospital database was searched for gastric MALT lymphoma diagnosed at the Tianjin Medical University Cancer Institute and Hospital, China, between August 2001 and August 2013. Histopathologic diagnosis of the gastric MALT lymphoma was made according to the World Health Organization classification (10). Histology and immunohistochemistry of the original histological samples (biopsy or resection specimens) were investigated, and reviewed by at least three histopathologists. Patients were excluded from the study subjects if: i) they had another malignancy at the time of diagnosis; ii) they were human immunodeficiency virus-positive cases; or iii) the follow-up period was $<12$ months. Following exclusion of those patients, the remaining 103 patients were included in the current study.

Staging procedures. The patients were restaged according to the Lugano staging system for gastrointestinal non-Hodgkin's lymphoma (11). The staging workup included patient history, physical examination, endoscopy, barium meal examination, chest X-ray or computed tomography scan, abdominal ultrasound and computed tomography scan, bone marrow aspiration and biopsy, gastric mucosal biopsies or gastrectomy as well as immunohistochemistry. The $H$. pylori infection status was determined by histologic examination, urea breath test, or both to evaluate the status of $H$. pylori infection following HPE. Routine laboratory tests, including measurement of hemoglobin, serum lactate dehydrogenase (LDH) and $\beta 2$-microglobulin $(\beta 2-\mathrm{MG})$, were also carried out in all 103 patients. Low hemoglobin was defined as $<120 \mathrm{~g} / \mathrm{l}$, high serum LDH as $>245 \mathrm{U} / \mathrm{l}$, and high $\beta 2-\mathrm{MG}$ as $>2.2 \mathrm{mg} / \mathrm{l}$.

Treatment modalities. Of the patients with localized gastric MALT lymphoma, 69 patients associated with $H$. pylori-positive and 4 patients with $H$. pylori-negative underwent HPE therapy. Other treatment modalities, such as RT and CT, were also used for treatment. The HPE regimen included proton pump inhibitors (omeprazole, lansoprazole, or rabeprazole) and a combination of antibiotics (amoxicillin, clarithromycin, and metronidazole). CT included monotherapy or a combination of CT and immunotherapy. RT was performed at a median total dose ranging from 26 to $46 \mathrm{~Gy}$. The response was assessed according to the international workshop for NHL standardized criteria (12).

Statistical analysis. Primary endpoints of the survival analysis were overall survival (OS) and progression-free survival (PFS). OS was measured from the date of diagnosis until the date of death due to any cause, or the date of survivors' final follow-up. The PFS was calculated from the time of diagnosis to the date of treatment failure, relapse, evidence of disease progression, or death due to any cause. The Kaplan-Meier method was used for survival estimations, and the log-rank test for survival comparisons. Variables that influenced the prognosis $(\mathrm{P}<0.05)$ in the univariate analysis were assessed by a multivariate analysis using the Cox regression model to determine independent prognostic factors for survival. The SPSS 17.0 software (SPSS, Inc., Chicago, IL, USA) was used
Table I. Characteristics of 103 patients with gastric MALT lymphoma.

\begin{tabular}{|c|c|}
\hline Feature & No. $(\%)$ \\
\hline \multicolumn{2}{|l|}{ Gender } \\
\hline Female & $51(50)$ \\
\hline Male & $52(50)$ \\
\hline \multicolumn{2}{|l|}{ Age } \\
\hline$\leq 60$ & $35(34)$ \\
\hline$>60$ & $38(66)$ \\
\hline \multicolumn{2}{|c|}{ Lugano staging } \\
\hline I-II2 & $75(73)$ \\
\hline IIE-IV & $28(27)$ \\
\hline \multicolumn{2}{|c|}{ Serum LDH level } \\
\hline Normal & $78(76)$ \\
\hline Abnormal & $25(24)$ \\
\hline \multicolumn{2}{|l|}{ B symptoms } \\
\hline Present & $51(50)$ \\
\hline Absent & $52(50)$ \\
\hline \multicolumn{2}{|c|}{$\beta 2$-microglobulin } \\
\hline Normal & $72(70)$ \\
\hline Abnormal & $31(30)$ \\
\hline \multicolumn{2}{|l|}{$\mathrm{m}-\mathrm{IPI}^{\mathrm{a}}$} \\
\hline $0-1$ & $78(76)$ \\
\hline$\geq 2$ & $15(15)$ \\
\hline Unknown & $10(9)$ \\
\hline \multicolumn{2}{|c|}{ Infection with $H$. pylori } \\
\hline Positive & $97(94)$ \\
\hline Negative & $6(6)$ \\
\hline \multicolumn{2}{|l|}{ Tumor mass } \\
\hline$<5 \mathrm{~cm}$ & $56(54)$ \\
\hline$\geq 5 \mathrm{~cm}$ & $34(33)$ \\
\hline Unknown & $13(13)$ \\
\hline \multicolumn{2}{|c|}{ Performance status } \\
\hline$<2$ & $72(70)$ \\
\hline$\geq 2$ & $15(15)$ \\
\hline Unknown & $16(15)$ \\
\hline \multicolumn{2}{|l|}{ Anemia } \\
\hline Present & $48(47)$ \\
\hline Absent & $55(53)$ \\
\hline
\end{tabular}

Adverse factors for ${ }^{\mathrm{a}} \mathrm{m}$-IPI (stage-m-IPI) included age $>60$ years, serum $\mathrm{LDH}>245 \mathrm{U} / 1, \mathrm{PS} \geq 2$, advanced stage, $\geq 1$ extranodal site involvement (excluding stomach). H. pylori, Helicobacter pylori; MALT, mucosaassociated lymphoid tissue; LDH, lactate dehydrogenase; m-IPI, modified-International Prognostic Index; PS, performance status.

for statistical analyses. $\mathrm{P}<0.05$ was considered to indicate a statistically significant difference.

\section{Results}

Patient characteristics. Patient characteristics are shown in Table I. Patients $(n=103)$ with gastric MALT lymphoma had 

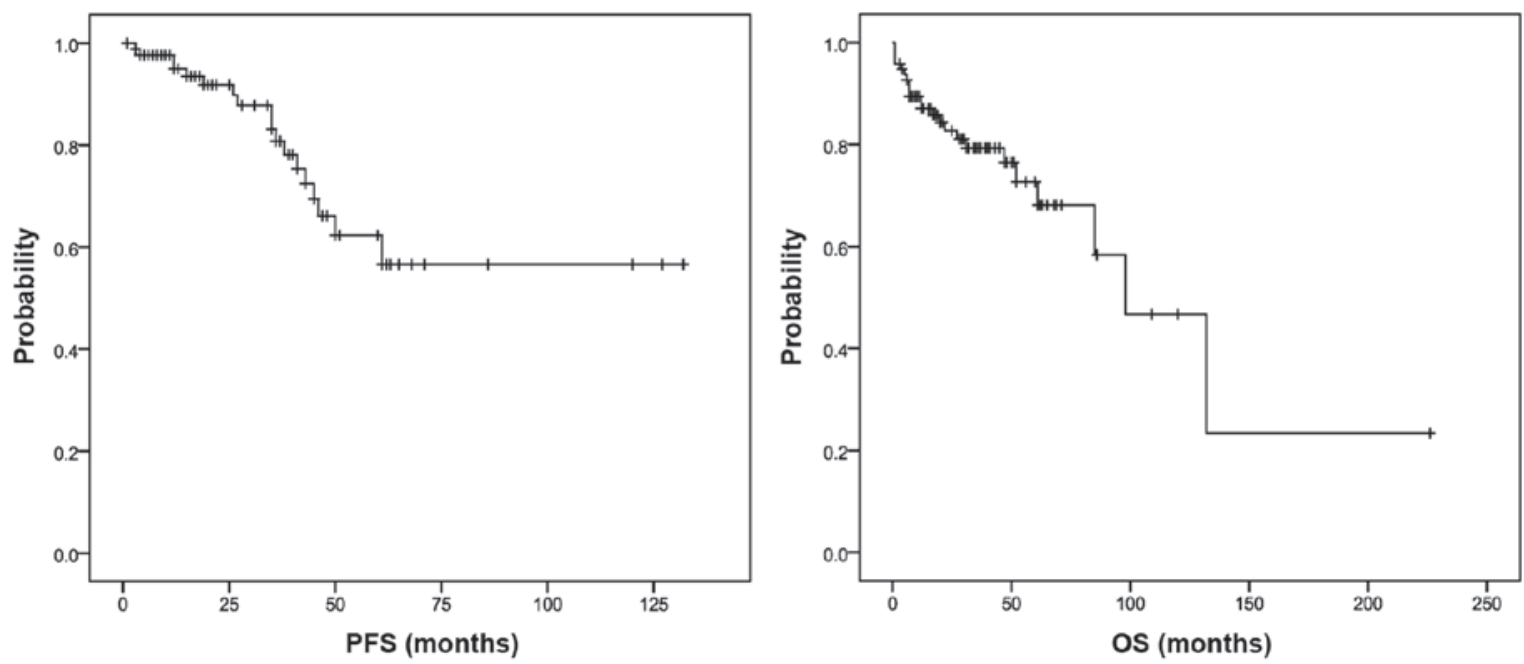

Figure 1. Survival curves for the entire population of patients with gastric mucosa-associated lymphoid tissue lymphoma. PFS, progression-free survival; OS, overall survival.

a median age of 53 years (range: 19-85 years), and included 54 males (M) and 49 females (F) at a ratio of 1:1. The onset of the disease was often insidious and without specific clinical manifestation. None of the patients experienced perforation prior to treatment. Their serum LDH and $\beta 2-\mathrm{MG}$ were usually within normal limits. In all 103 patients, the diagnosis was made on the basis of an endoscopic biopsy. Macroscopically, the most commonly involved site was the antrum (60.7\%), followed by the corpus (51.6\%), and fundus (23.5\%). Most patients appeared ulcerative (78.4\%). Using the Lugano staging system, 40 patients (39\%) had stage I, and 35 patients (35\%) were diagnosed with local or distant nodal involvement. There were also patients with stage IIIE $(20 / 103,19 \%)$ and stage IV $(8 / 103,7 \%)$ disease.

HPE. The H. pylori infection rate was $94 \%$ (97/103), whereas the infection rate was $100 \%(28 / 28)$ in patients with advanced stages. A total of 73 patients with localized disease, including 69 patients associated with $H$. pylori-positive and 4 patients with $H$. pylori-negative, received HPE as a first-line treatment. H. pylori was eradicated in all the positive patients (69/69), although in 17 of these patients, a second-line HPE was required. The symptoms disappeared or were markedly reduced in the majority of patients. The CR was achieved in 54 of the 69 patients $(78 \%)$ with $H$. pylori-positive and in 2 of the 4 patients (50\%) with $H$. pylori-negative. The median time to complete remission (CR) after HPE was 4 months (range: 3-9 months). HPE had a superior trend in the $H$. pylori-positive patients but was not significantly different in the two groups $(\mathrm{p}=0.194)$.

Other treatment modalities. The 16 patients, including 14 patients who failed to achieve CR by HPE and 2 patients associated with $H$.pylori-negative, received RT. The remaining 3 patients who failed to achieve CR by HPE were followed on watch-and-wait strategy due to improved endoscopic features and relief symptoms. The success rate of RT was $100 \%$ (16/16). Of note, the 3 patients treated by watch-and-wait strategy, only 1 had disease recurrence by gastric $H$. pylori reinfection and a second remission was obtained following a second-line HPE.

Of the 28 patients with advanced stages, 12 patients received CT or RT combined with HPE and H. pylori was eradicated in the 12 patients. CR was achieved in 8 of the 12 patients (67\%). The remaining 16 patients received CT or RT. The CR was achieved in 10 of the 16 patients (63\%). There was no statistical difference in the two groups $(\mathrm{p}=0.820)$.

Survival analysis. The median follow-up time was 62.9 months (range: 1-226 months). The median PFS was 41.5 months (range: 1-132 months), and the median OS was 59.5 months (range: 2-226 months). The 5-year PFS and OS estimates for the 103 patients were 58 and $69 \%$, respectively (Fig. 1). The 5 -year PFS and OS estimates were compared between patients receiving $\mathrm{CT}$ or RT combined with HPE and those receiving CT or RT. We found that the five-year PFS and OS estimates were significantly improved ( $<<0.05$, Fig. 2) for patients receiving CT or RT combined with HPE than those receiving CT or RT.

Based on the univariate analysis, the B symptoms, serum $\mathrm{LDH}>245 \mathrm{U} / 1, \beta 2-\mathrm{MG}>2.2 \mathrm{mg} / 1$, advanced stages, $\mathrm{PS} \geq 2$ and modified-International Prognostic Index (m-IPI) $(\geq 2)$ adversely affected PFS and OS (Table II). Advanced stages were significant only for shorter PFS, and m-IPI $(\geq 2)$ retained its prognostic significance for the shorter OS with multivariate analysis (Table III).

\section{Discussion}

Gastric MALT lymphoma is an indolent disease with a prolonged clinical course that most often involves the stomach (3). The clinical presentation is similar to gastric carcinomas and benign ulcers, and commonly includes abdominal pain or discomfort, and with less frequent signs such as bleeding and perforation. The duration of the symptoms prior to diagnosis is variable, ranging from a few weeks to several years. B symptoms are exceedingly rare, and adverse biological prognostic factors such as high serum LDH and $\beta 2-\mathrm{MG}$ levels are infrequently elevated. H. pylori is linked to 
Table II. Univariate analysis of prognostic factors for PFS and OS.

\begin{tabular}{|c|c|c|c|c|}
\hline \multirow[b]{2}{*}{ Clinical characteristics } & \multicolumn{2}{|c|}{ OS } & \multicolumn{2}{|c|}{ PFS } \\
\hline & $\chi^{2}$ test & p-value & $\chi^{2}$ test & p-value \\
\hline Age & 3.118 & 0.077 & 0.795 & 0.373 \\
\hline Gender & 0.030 & 0.864 & 0.450 & 0.502 \\
\hline B symptoms & 5.025 & 0.025 & 10.449 & 0.001 \\
\hline Anemia & 1.508 & 0.208 & 0.511 & 0.475 \\
\hline Serum LDH > 245 U/1 & 6.213 & 0.013 & 7.261 & 0.007 \\
\hline$\beta 2$-microglobulin $>2.2 \mathrm{mg} / \mathrm{l}$ & 9.604 & 0.002 & 8.098 & 0.004 \\
\hline Tumor mass $\geq 10 \mathrm{~cm}$ & 3.873 & 0.275 & 4.215 & 0.239 \\
\hline H.pylori-positive & 2.747 & 0.253 & 4.238 & 0.120 \\
\hline Advanced stages & 4.028 & 0.045 & 4.930 & 0.026 \\
\hline $\mathrm{PS} \geq 2$ & 5.998 & 0.014 & 74.897 & 0.000 \\
\hline$m-I P I \geq 2$ & 5.784 & 0.017 & 4.389 & 0.036 \\
\hline
\end{tabular}

PFS, progression-free survival; OS, overall survival; LDH, lactate dehydrogenase; H. pylori, Helicobacter pylori; PS, performance status; m-IPI, modified-International Prognostic Index.

Table III. Factors retaining prognostic significance for PFS and OS with multivariate and Cox proportional hazards analysis.

\begin{tabular}{|c|c|c|c|c|c|c|}
\hline \multirow[b]{2}{*}{ Prognostic factors } & \multicolumn{3}{|c|}{ OS } & \multicolumn{3}{|c|}{ PFS } \\
\hline & Relative risk & $95 \% \mathrm{CI}$ & p-value & Relative risk & $95 \% \mathrm{CI}$ & p-value \\
\hline B symptoms & 4.982 & $0.000-0.548$ & 0.246 & 0.191 & $0.311-2.172$ & 0.514 \\
\hline Serum LDH > 245 U/1 & 4.266 & $1.216-17.132$ & 0.069 & 2.029 & $0.165-3.517$ & 0.917 \\
\hline$\beta 2$-microglobulin $>2.2 \mathrm{mg} / 1$ & 1.564 & $0.467-31.345$ & 0.211 & 1.273 & $0.417-3.218$ & 0.287 \\
\hline Advanced stages & 2.936 & $0.002-1.524$ & 0.087 & 1.157 & $0.924-11.627$ & 0.028 \\
\hline $\mathrm{PS} \geq 2$ & 0.620 & $0.272-21.203$ & 0.431 & 2.137 & $0.056-1.087$ & 0.106 \\
\hline $\mathrm{m}-\mathrm{IPI} \geq 2$ & 6.937 & $3.721-77.677$ & 0.008 & 4.682 & $0.826-11.235$ & 0.076 \\
\hline
\end{tabular}

PFS, progression-free survival; OS, overall survival; CI, confidence interval; LDH, lactate dehydrogenase; PS, performance status; m-IPI, modified-International Prognostic Index.
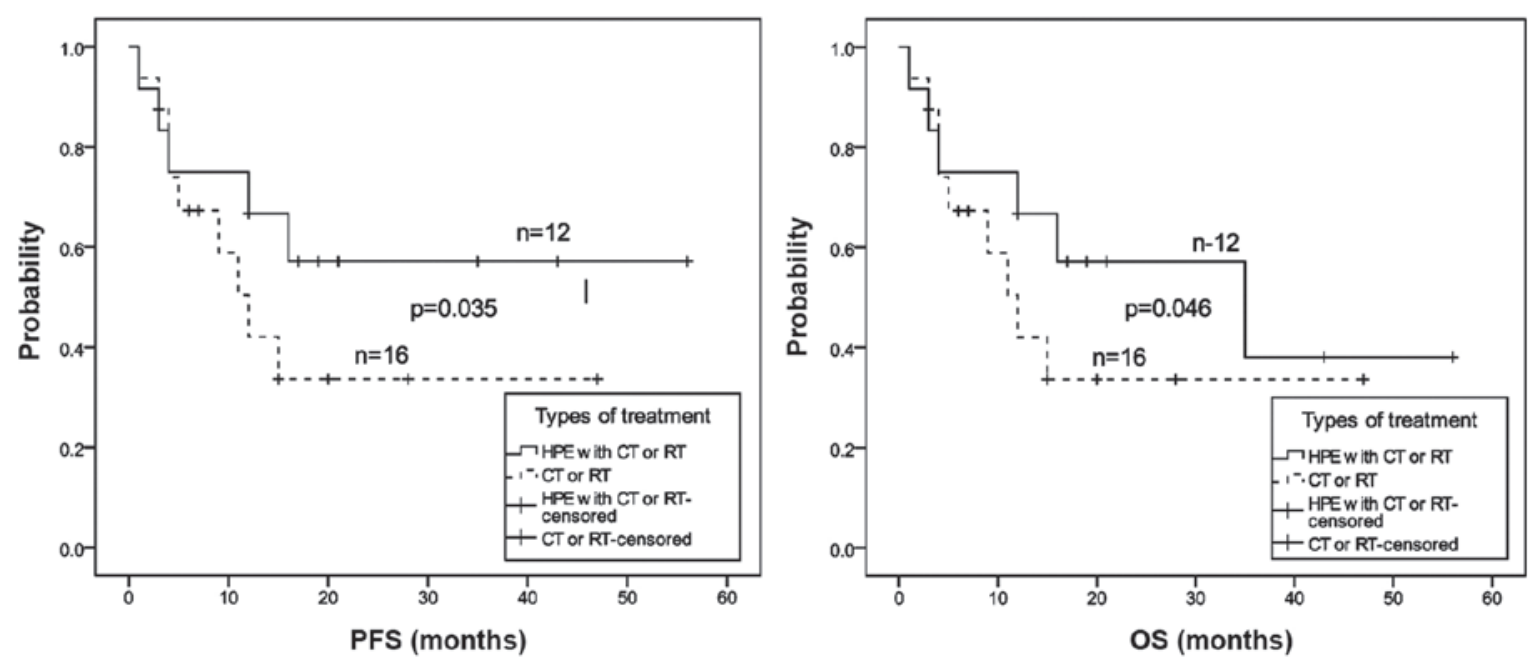

Figure 2. For patients with advanced (IIE and IV) diseases, the effects of Helicobacter pylori eradication (HPE) with chemotherapy (CT) or radiotherapy (RT) were significantly better than CT or RT on 5-year progression-free survival (PFS) and overall survival (OS) estimates. 
the development of gastric MALT lymphoma (12), and they occurred frequently in the present study. The clinical characteristics of gastric MALT lymphoma in the present study are similar to those reported in previous studies $(3,13,14)$.

Identification of the etiologic role of $H$. pylori infection in gastric MALT lymphoma has radically changed the therapeutic approach for such neoplasia. Following successful HPE, lymphoma remission was achieved in $77.5 \%$ of 1,408 patients with gastric MALT lymphoma at the early stages with a median time of 5 months (15). In the present study, we found that the remission of gastric MALT lymphoma was achieved after HPE in 56 patients $(77 \%)$ of 73 patients with localized disease. This figure was comparable to the results of several reported large cases (16-18). Of note, in the present study, 2 patients with $H$. pylori-negative successfully achieved CR by HPE and there were no significant differences in the CR rate following HPE between the $H$. pylori-positive and -negative groups, which is consistent with a previous study (19). Eradication therapy may be useful for $H$. pylori-negative gastric MALT lymphoma: first, another infective organism such as Helicobacter heilmannii, might be involved in the development of gastric MALT lymphoma (20); second, because of very low bacterial counts, conventional examination did not detect the organisms (21). Currently, unlike that for $H$. pylori-positive MALT lymphoma, the optimal management of $H$. pylori-negative MALT lymphoma remains controversial. These findings suggest that HPE therapy may be considered as a first-line treatment regardless of $H$. pylori infection status. In addition, there was no difference in 5-year OS between patients who received CT or RT with HPE and those receiving CT or RT. Patients who received CT or RT combined with HPE had an improved 5-year PFS and OS than those who received CT or RT. This result suggests that HPE may improve the prognosis of advanced stages of gastric MALT lymphoma. Since advanced gastric MALT lymphoma is likely a progression from localized to extensive disease, they may still be completely cured by HPE. According to the currently published European Society of Medical Oncology guidelines, HPE should be administered to all gastric MALT lymphomas, independent of the stages and even in $H$. pylori-negative cases (22). However, large-scale prospective randomized clinical trials are needed to document any HPE benefits for patients with gastric MALT lymphoma.

There are no accepted prognostic factors for gastric MALT lymphoma thus far. A recent study by Wirth et al (23) showed that there was a trend to the poorer outcome with increasing age, lymph node involvement and stomach wall thickening. Previous studies $(6,24)$ described the grade of malignancy and stage of the disease as the two major prognostic factors. Translocation $\mathrm{t}(11 ; 18)$, the most common genetic aberration in gastric MALT lymphomas is associated with poorer outcome as it strongly predicts the response of gastric MALT lymphoma to HPE (25). The IPI has been correlated with relapse, while the utility of IPI is controversial. Previous studies $(26,27)$ have demonstrated that stage m-IPI is an effective predictive factor for patients with gastric lymphoma, where m-IPI was more accurate than the IPI for predicting gastric lymphoma patient survival. In our analysis, stage m-IPI was identified as an independent prognostic factor for OS in the multivariate analysis. Patients in the low-risk group ( $m$-IPI $\leq 1)$ had significantly longer survival than the intermediate/high-risk $(\mathrm{m}-\mathrm{IPI} \geq 2)$ patients. Our multivariate analysis revealed that advanced stage of lymphoma was an independent prognostic factor for PFS. Previous findings $(27,28)$ have also shown that the prognosis for gastric lymphoma is influenced by the depth of infiltration and is exacerbated with metastasis to other organs. Ranaldi et al (29) showed there was no difference in the survival rate between stages I and II gastric lymphoma. However, there was a trend for increasing hazard as the neoplasia progresses from stages II to IIE ( $p=0.001)$. We believe that advanced lymphoma stages are crucial for prognostic evaluation, although the exact relationship between disease stage and outcomes remains to be established. Studies identifying other prognostic markers remain to be undertaken.

In conclusion, the results of the present study confirm the indolent course of gastric MALT lymphoma with late relapse and prolonged survival. The patients with advanced stages and m-IPI ( $\geq 2)$, however, tend to have a worse prognosis. As an effective treatment for gastric MALT lymphoma, HPE therapy should be administered to all gastric MALT lymphomas, independently of stage and even in $H$.pylori-negative cases.

\section{Acknowledgements}

The authors would like to thank the medical staff who contributed to the success of the present study.

\section{References}

1. Zucca E and Cavalli F: Extranodal lymphomas. Ann Oncol 11 (Suppl 3): 219-222, 2000.

2. Du MQ and Atherton JC: Molecular subtyping of gastric MALT lymphomas: Implications for prognosis and management. Gut 55: 886-893, 2006.

3. Psyrri A, Papageorgiou S and Economopoulos T: Primary extranodal lymphomas of stomach: clinical presentation, diagnostic pitfalls and management. Ann Oncol 19: 1992-1999, 2008.

4. Zullo A, Hassan C, Andriani A, Cristofari F, De Francesco V, Ierardi E, Tomao S, Morini S and Vaira D: Eradication therapy for Helicobacter pylori in patients with gastric MALT lymphoma: a pooled data analysis. Am J Gastroenterol 104: 1932-1937, quiz $1938,2009$.

5. Ruskoné-Fourmestraux A, Fischbach W, Aleman BM, Boot H, Du MQ, Megraud F, Montalban C, Raderer M, Savio A and Wotherspoon A; EGILS group: EGILS consensus report. Gastric extranodal marginal zone B-cell lymphoma of MALT. Gut 60: 747-758, 2011.

6. Radaszkiewicz T, Dragosics B and Bauer P: Gastrointestinal malignant lymphomas of the mucosa-associated lymphoid tissue: Factors relevant to prognosis. Gastroenterology 102: 1628-1638, 1992.

7. Ruskoné-Fourmestraux A, Aegerter P, Delmer A, Brousse N, Galian A and Rambaud JC: Primary digestive tract lymphoma: a prospective multicentric study of 91 patients. Groupe d'Etude des Lymphomes Digestifs. Gastroenterology 105: 1662-1671, 1993.

8. Liu H, Ye H, Ruskone-Fourmestraux A, De Jong D, Pileri S, Thiede C, Lavergne A, Boot H, Caletti G, Wündisch T, et al: $\mathrm{T}(11 ; 18)$ is a marker for all stage gastric MALT lymphomas that will not respond to $H$. pylori eradication. Gastroenterology 122 : 1286-1294, 2002.

9. Yeh KH, Kuo SH, Chen LT, Mao TL, Doong SL, Wu MS, Hsu HC, Tzeng YS, Chen CL, Lin JT, et al: Nuclear expression of BCL10 or nuclear factor kappa B helps predict Helicobacter pylori-independent status of low-grade gastric mucosa-associated lymphoid tissue lymphomas with or without $\mathrm{t}(11 ; 18)(\mathrm{q} 21 ; \mathrm{q} 21)$. Blood 106: 1037-1041, 2005.

10. Tomonaga M: Outline and direction of revised WHO classification of Tumors of Haematopoietic and Lymphoid Tissues. Rinsho Ketsueki 50: 1401-1406, 2009 (In Japanese). 
11. Rohatiner A, d'Amore F, Coiffier B, Crowther D, Gospodarowicz M, Isaacson P, Lister TA, Norton A, Salem P, Shipp M, et al: Report on a workshop convened to discuss the pathological and staging classifications of gastrointestinal tract lymphoma. Ann Oncol 5: 397-400, 1994.

12. Wotherspoon AC, Doglioni C, Diss TC, Pan L, Moschini A, de Boni M and Isaacson PG: Regression of primary low-grade B-cell gastric lymphoma of mucosa-associated lymphoid tissue type after eradication of Helicobacter pylori. Lancet 342: 575-577, 1993.

13. Nakamura S, Matsumoto T, Iida M, Yao T and Tsuneyoshi M: Primary gastrointestinal lymphoma in Japan: a clinicopathologic analysis of 455 patients with special reference to its time trends. Cancer 97: 2462-2473, 2003.

14. Kolve M, Fischbach W, Greiner A and Wilms K; German Gastrointestinal Lymphoma Study Group: Differences in endoscopic and clinicopathological features of primary and secondary gastric non-Hodgkin's lymphoma. Gastrointest Endosc 49: 307-315, 1999.

15. Zullo A, Hassan C, Cristofari F, Andriani A, De Francesco V, Ierardi E, Tomao S, Stolte M, Morini S and Vaira D: Effects of Helicobacter pylori eradication on early stage gastric mucosa-associated lymphoid tissue lymphoma. Clin Gastroenterol Hepatol 8: 105-110,2010.

16. Wündisch T, Thiede C, Morgner A, Dempfle A, Günther A, Liu H, Ye H, Du MQ, Kim TD, Bayerdörffer E, et al: Long-term follow-up of gastric MALT lymphoma after Helicobacter pylori eradication. J Clin Oncol 23: 8018-8024, 2005.

17. Fischbach W, Goebeler ME, Ruskone-Fourmestraux A Wündisch T, Neubauer A, Raderer M and Savio A; EGILS (European Gastro-Intestinal Lymphoma Study) Group: Most patients with minimal histological residuals of gastric MALT lymphoma after successful eradication of Helicobacter pylori can be managed safely by a watch and wait strategy: experience from a large international series. Gut 56: 1685-1687, 2007.

18. Vivas S, Ruiz de Morales JM, Fernandez M, Hernando M, Herrero B, Casqueiro J and Gutierrez S: Age-related clinical, serological, and histopathological features of celiac disease. Am J Gastroenterol 103: 2360-2365, quiz 2366, 2008.

19. Raderer M, Streubel B, Wöhrer S, Häfner M and Chott A: Successful antibiotic treatment of Helicobacter pylori negative gastric mucosa associated lymphoid tissue lymphomas. Gut 55: 616-618, 2006

20. Morgner A, Lehn N, Andersen LP, Thiede C, Bennedsen M, Trebesius K, Neubauer B, Neubauer A, Stolte $M$ and Bayerdörffer E: Helicobacter heilmannii-associated primary gastric low-grade MALT lymphoma: Complete remission after curing the infection. Gastroenterology 118: 821-828, 2000.
21. Steinbach G, Ford R, Glober G, Sample D, Hagemeister FB, Lynch PM, McLaughlin PW, Rodriguez MA, Romaguera JE, Sarris AH, et al: Antibiotic treatment of gastric lymphoma of mucosa-associated lymphoid tissue. An uncontrolled trial. Ann Intern Med 131: 88-95, 1999.

22. Zucca E, Copie-Bergman C, Ricardi U, Thieblemont C, Raderer M and Ladetto M; ESMO Guidelines Working Group: Gastric marginal zone lymphoma of MALT type: ESMO Clinical Practice Guidelines for diagnosis, treatment and follow-up. Ann Oncol 24 (Suppl 6): vi144-vi148, 2013.

23. Wirth A, Gospodarowicz M, Aleman BM, Bressel M, Ng A, Chao M, Hoppe RT, Thieblemont C, Tsang R, Moser L, et al: Long-term outcome for gastric marginal zone lymphoma treated with radiotherapy: a retrospective, multi-centre, International Extranodal Lymphoma Study Group study. Ann Oncol 24: 1344-1351, 2013.

24. Cogliatti SB, Schmid U, Schumacher U, Eckert F, Hansmann ML, Hedderich J, Takahashi $\mathrm{H}$ and Lennert K: Primary B-cell gastric lymphoma: a clinicopathological study of 145 patients. Gastroenterology 101: 1159-1170, 1991.

25. Lima KS, Albuquerque W, Arantes VN, Drummond-Lage AP and Coelho LG: Helicobacter pylori and t(11;18)(q21;q21) translocation in gastric malt lymphoma. Arq Gastroenterol 51: 84-89, 2014.

26. Cortelazzo S, Rossi A, Roggero F, Oldani E, Zucca E, Tondini C, Ambrosetti A, Pasini F, Pinotti G, Bertini M, et al; International Extranodal Lymphoma Study Group (IELSG): Stage-modified international prognostic index effectively predicts clinical outcome of localized primary gastric diffuse large B-cell lymphoma. Ann Oncol 10: 1433-1440, 1999.

27. Leopardo D, Di Lorenzo G, De Renzo A, Federico P, Luponio S, Buonerba C, Matano E, Merola G, Imbimbo M, Montesarchio E, et al: Efficacy of rituximab in gastric diffuse large B cell lymphoma patients. World J Gastroenterol 16: 2526-2530, 2010

28. Medina-Franco H, Germes SS and Maldonado CL: Prognostic factors in primary gastric lymphoma. Ann Surg Oncol 14: 2239-2245, 2007.

29. Ranaldi R, Goteri G, Baccarini MG, Mannello B and Bearzi I: A clinicopathological study of 152 surgically treated primary gastric lymphomas with survival analysis of 109 high grade tumours. J Clin Pathol 55: 346-351, 2002. 